\title{
Hemato-biochemical and pathological changes on avian influenza in naturally infected domestic ducks in Egypt
}

\author{
Essam A. Mahmoud \\ Department of Clinical Pathology, Faculty of Veterinary Medicine, Zagazig University, Zagazig City, Sharkia Province, Egypt. \\ Corresponding author: Essam A. Mahmoud, e-mail: essammahmoud97@yahoo.com \\ Received: 22-05-2015, Revised: 29-08-2015, Accepted: 07-09-2015, Published online: 09-10-2015 \\ doi: 10.14202/vetworld.2015.1177-1182 How to cite this article: Mahmoud EA (2015) Hemato-biochemical and \\ pathological changes on avian influenza in naturally infected domestic ducks in Egypt, Veterinary World 8(10): 1177-1182.
}

\begin{abstract}
Aim: Few studies have been made in regard to avian influenza (AI) in ducks, thus the aim of this work was planned to investigate the hematological, biochemical, and pathological changes in domestic Egyptian ducks naturally infected with AI.

Materials and Methods: 30 duck from private backyards 3-month-old 15 were clinically healthy (Group 1) and the other fifteen (Group 2) were naturally diseased with AI (H5N1). The disease was diagnosed by polymerase chain reaction as H5N1.

Results: Duck showed cyanosis, subcutaneous edema of head and neck with nervous signs (torticollis). Hematological studies revealed a microcytic hypochromic anemia. Biochemical studies revealed a significant decrease in total protein, albumin and globulin concentration with significant increase of activities of aspartate aminotransferase, alanine aminotransferase, alkaline phosphatase, Y-glutamyl transpeptidase, lactic acid dehydrogenase and creatine phsphokinase. Prominent increase in creatinine and uric acid in addition to hypocalcemia and hyperphosphatemia were significantly detected in the infected ducks. Histopathological finding confirm these investigations.
\end{abstract}

Conclusion: The highly pathogenic AIV (A/H5N1) became more severe infectious to ducks than before and causes nervous manifestations and blindness which were uncommon in ducks. Besides the significant increases of hepatic enzymes, brain, heart, and renal markers as a response to virus damage to these organs.

Keywords: aminotranseferases, anemia, avian influenza, creatinine, ducks, uric acid.

\section{Introduction}

Avian influenza viruses (AIV) threaten most of live beings around the world from the onset of the third millennium. This hazard comes from the zoonotic and lethal effect of these viruses. Lately, several zoonotic avian influenza (AI) A strains have been reported to directly infect humans [1]. The spread of highly pathogenic AIV (A/H5N1) from Asia to Africa in 2005 was considered as a global epidemiological twist. The first entrance of A/H5N1 to Egypt recorded in mid-February 2006 which accompanied enormous losses in poultry industry [2]. Highly pathogenic AIV was one of the first viral diseases described in poultry. Infections with AIV of low and high pathogenicity are commonly reported in domestic ducks in many parts of the world [3]. Normally AI viruses, including the highly pathogenic $\mathrm{H} 5$ and $\mathrm{H} 7$ strains, do not cause disease or death in ducks [4]. Mortality in naturally infected ducks with AI viruses was first recorded during an outbreak of HPAI virus in Italy in 2001 [5]. Since then, a number of H5N1 HPAI viruses cause diseases in ducks $[4,6,7]$. Clinical signs were recorded on ducks with variable degrees. Ducks appeared more passive, fluffed feathers, conjunctivitis, and slight depression, and progressed over a period to severe

Copyright: The authors. This article is an open access article licensed under the terms of the Creative Commons Attributin License (http:// creative commons.org/licenses/by/2.0) which permits unrestricted use, distribution and reproduction in any medium, provided the work is properly cited. neurologic signs consisting of torticollis, in coordination, tremors, cloudy eyes and blindness. The only gross lesion observed at postmortem examination was congested lungs and liver [8].

A highly pathogenic AI (HPAI) $\mathrm{A}(\mathrm{H} 5 \mathrm{~N} 1)$ virus was first detected in China in 1996 [9]. The disease (A/H5N1) spread from Asia to Africa in 2005 [2]. The avian influenza (HPAI) viruses cause high morbidity and mortality levels in chickens and ducks and other waterfowl $[10,11]$. The virus (HPAI) H5N1 transformed from sporadic outbreaks in poultry to persistent circulation in terrestrial and aquatic poultry and potentially in wild waterfowl [12]. In addition leading to, serious economic losses in the poultry industry [13]. Outbreaks associated with the AIV have increased since 2009 [14].

The aim of this study was to investigate the hematological, blood chemistry, and pathological changes in domestic ducks naturally infected with HPAI.

\section{Materials and Methods}

\section{Ethical approval}

Ethical approval was conducted in accordance with the guidelines set by Animals Health Research Ethics Training Initiative, Egypt, and experimental protocols were approved by the Institutional Animal Ethics Committee.

\section{Animals and methods}

30 ducks, 3-month-old, 15 ducks were clinically healthy (Group 1) and the other 15 ducks (Group 2) 
were naturally diseased with avian influenza (H5N1) were obtained from private backyards in Sharkia governorate and used in this work. Two blood samples were collected at the same time from wing vein from Groups 1 to 2 . The first set of blood samples $(0.5 \mathrm{ml}$ from each duck) were collected in dipotassium salt of ethylene diamine tetra acetic acid (EDTA) tubes to be used for estimation of the erythrocytic and total leukocytic counts [15], packed cell volume [16] and hemoglobin using the cyanmethemoglobin colorimeteric method [17]. The differential and absolute leukocytic counts were carried out [16]. While the second set of blood samples ( $5 \mathrm{ml}$ from each duck) were taken without anticoagulant in a sterile test tubes for separation of serum for determination of serum aspartate aminotransferase (AST) and alanine aminotransferase (ALT) [18], Y-glutamyl transpeptidase (GGT) [19], lactic acid dehydrogenase (LDH) [20], creatinine [21], uric acid [22], calcium [23], and inorganic phosphorus [24]. Protein electrophoresis was quantitatively measured [25].

\section{Histopathological examination}

Duck were necropsied and specimens were collected from the liver, kidneys, lungs and trachea. The specimens were fixed in $10 \%$ buffered neutral formalin solution, dehydrated in gradual ethanol (70-100\%), cleared in xylene, and embedded in paraffin. 5- $\mu$ thickness paraffin sections were prepared and then routinely stained with hematoxylin and eosin (H and $\mathrm{E})$ dyes. The sections were mounted with Canada balsam and covered with cover slide to be ready for histopathological examination [26].

\section{Diagnosis of the disease (polymerase chain reaction [PCR])}

Viral RNA were propagated in embryonated chicken eggs for obtaining allantoic fluid samples (HA positive). Allantoic fluid was purified using Gene JET ${ }^{\mathrm{TM}}$ RNA purification kit (Fermentas) according to the manufacturer's instructions. The cDNAs were synthesized using Revert $\mathrm{Aid}^{\mathrm{TM}} \mathrm{H}$ minus first strand cDNA synthesis kit (Fermentas \#K1631) according to the manufacturer's instructions. Primers used for HA gene amplification are forward H5-kha-1: 5'-CCTCCAGARTATGC MTAYAAAATTGTC-3` and reverse H5-kha-3: 5'-TA CCAACCGTCTACCATKCCYTG-3` to amplify a portion of the HA gene spanning the HA cleavage site [27]. The PCR was performed in a total volume of $25 \mu$ in a sterile $0.2 \mathrm{ml}$ RNase free PCR tube. The reaction was carried out using thermocycler with the following temperature profile: $3 \mathrm{~min}$ at $95^{\circ} \mathrm{C}$ (initial denaturation) followed by 30 cycles of $30 \mathrm{sec}$ at $95^{\circ} \mathrm{C}$ (denaturation), $30 \mathrm{sec}$ at $52^{\circ} \mathrm{C}$ (annealing) and $90 \mathrm{sec}$ at $72^{\circ} \mathrm{C}$ (elongation), and 15 min at $72^{\circ} \mathrm{C}$ (final elongation). Amplicons with a size of $\sim 317$ bp were visualized by $1.5 \%$ agarose gel electrophoresis in Tris-acetate EDTA buffer.

\section{Statistical analysis}

The data obtained from this investigation were statistically analyzed using Student's t-test [28].

\section{Results and Discussion}

Highly pathogenic AIV (HPAIV) H5N1 has been endemic in Egypt since 2006, and there is increasing concern for its potential to become highly transmissible among humans [29]. Ducks were reared in private backyards in Sharkia governorate, Egypt, during December 2014 until February 2015. The recorded clinical symptoms were previously mentioned by several investigators $[30,31]$. HPAIV H5N1 has been confirmed using PCR (Figure-1). Some ducks developing clinical disease and others remaining sub clinically infected. Such outcome not only depends on the bird species, but also on the infection dose [32]. Clinically, diseased ducks became sick with symptoms including cyanosis, subcutaneous edema of head and neck and nervous signs (torticollis) (Figures-2 and 3) and began to die within 2-3 days of the onset of clinical symptoms. This is confirmed with sever congestion and hemorrhage of the lung and subcutaneous edema $[33,34]$, congestion and mild desquamation of the trachea (Figures-4 and 5). Nervous signs (torticollis) which seen in the diseased duck could be due to the virus reach the CNS through the olfactory nerves, the peripheral nervous system [35], or

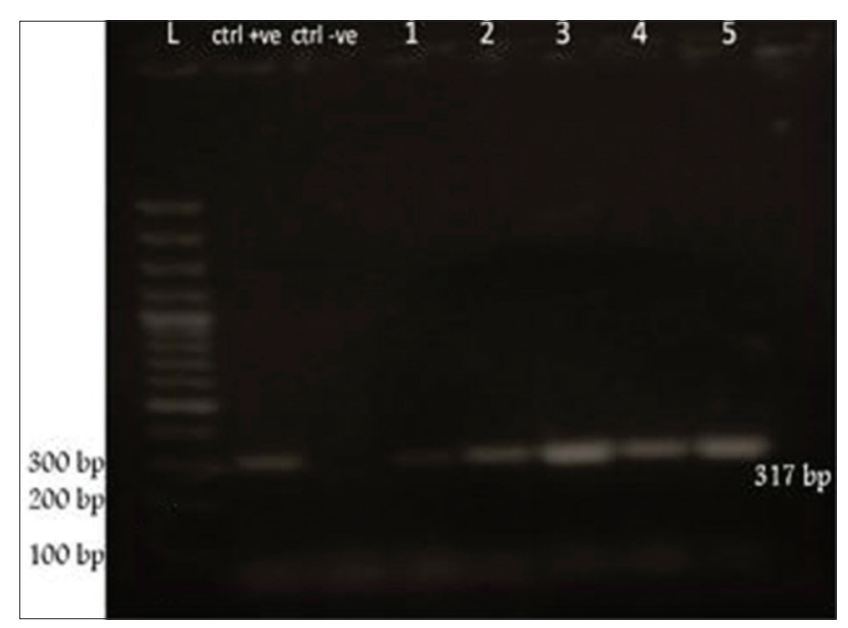

Figure-1: Polymerase chain reaction result.

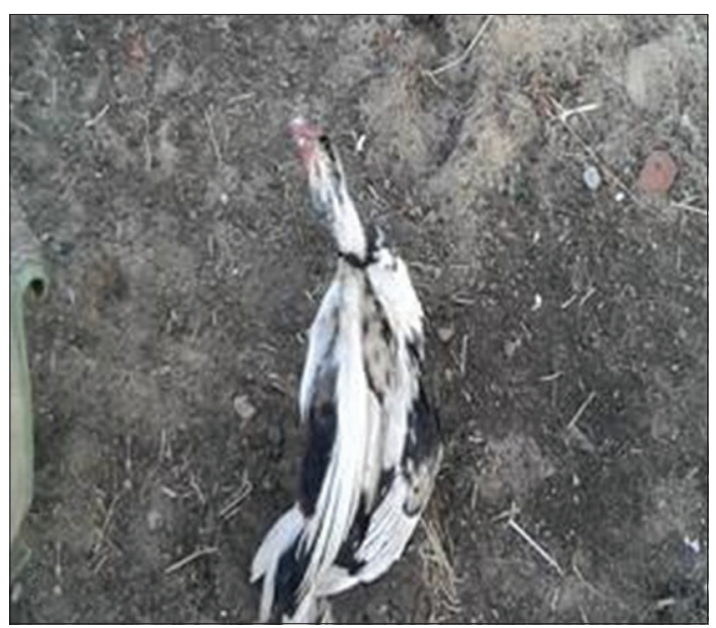

Figure-2: Ducks showed depression and in coordination (Group 2). 
even via bloodstream [36]. Most recent research [31] concluded that viral antigen were observed in endothelial cells of brain, which provides direct evidence that the HPAIV H5N1 likely invades the CNS by replicating in blood vessels in the brain, which probably one of the main causes for mortality.

Regarding to erythrogram (Table-1) there was a microcytic hypochromic anemia. This anemia could be due to the hemorrhages present in the different organs or due to a decreased erythropoiesis as a result of the kidney damaged. Thrompocytopenia could be due to systemic viral infection [37] which could facilities the hemorrhagic process [38]. While leucopenia (Table-2) is due to lymphopenia and heteropenia which returned to the direct damage effect of the AIV, rather than its replication, depleting the cells from essential components [39]. Also, Acland et al. [40] reported a depletion of the lymphocytes from the white pulp of the spleen in avian influenza outbreaks in broiler and layer chickens (H5N3).

Proteinogram (Table-3) revealed hypoproteinemia, hypoalbuminemia and hypoglobulinemia. The hypoproteinemia and hypoalbuminemia may be due to the decreased feed intake, loss through intestine and/or disturbed metabolism of the liver, in addition to the effect of AIV on the kidneys which leads to albuminuria. Hypoglobulinemia either alpha globulins, beta globulins, or gamma globulins tabulate the immunosuppressive effect of AIV [41].

Regarding to results of liver function tests (Table-4) revealed a significant increase of aminotransferases activities (AST and ALT) and ALP that could be due to liver involvement [42]. These results were confirmed with the presence of degenerative and necrotic changes in hepatic tissue and hemorrhage in portal area (Figure-6). While a significant increase of GGT, LDH, and creatine phsphokinase may be due to liver, kidney, and/or brain dysfunction [43,44]. On the other side, renal function tests (Table-5) appears a significant increase in both of serum creatinine and uric acid as a result of renal tissue damage [45].

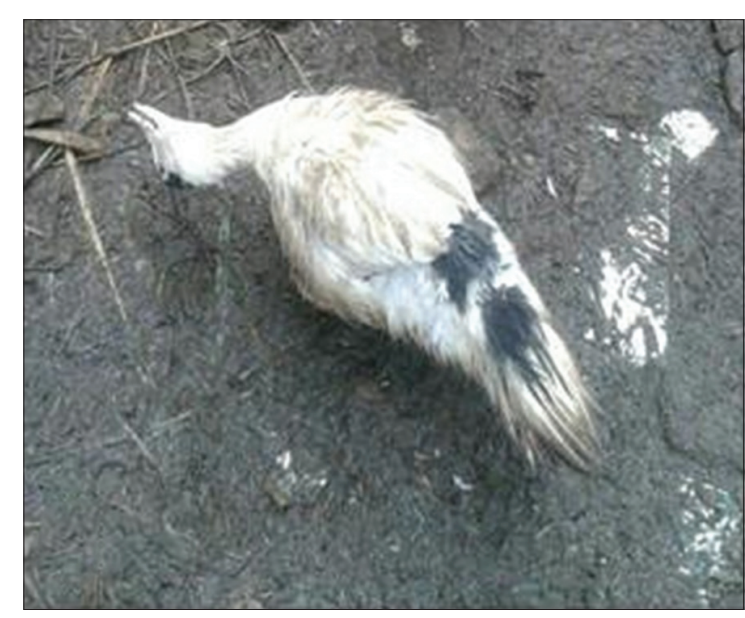

Figure-3: Nervous manifestation (torticollis) (Group 2).

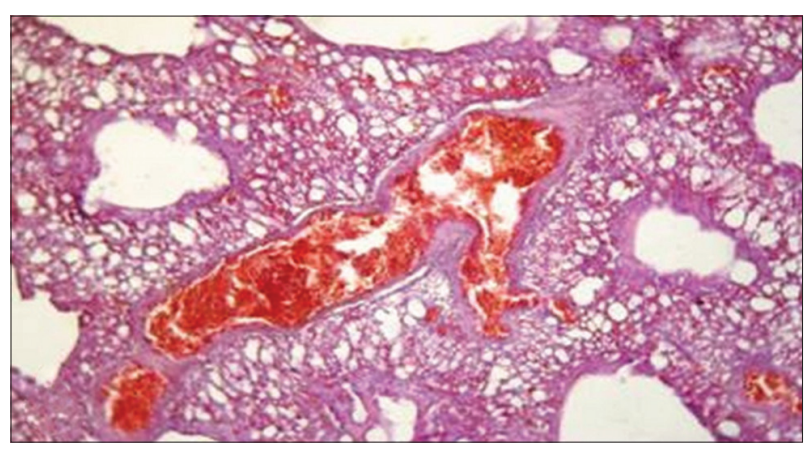

Figure-4: Lung showing severe congestion and hemorrhage $(\mathrm{H}$ and $\mathrm{E}, \times 300)($ Group 2).

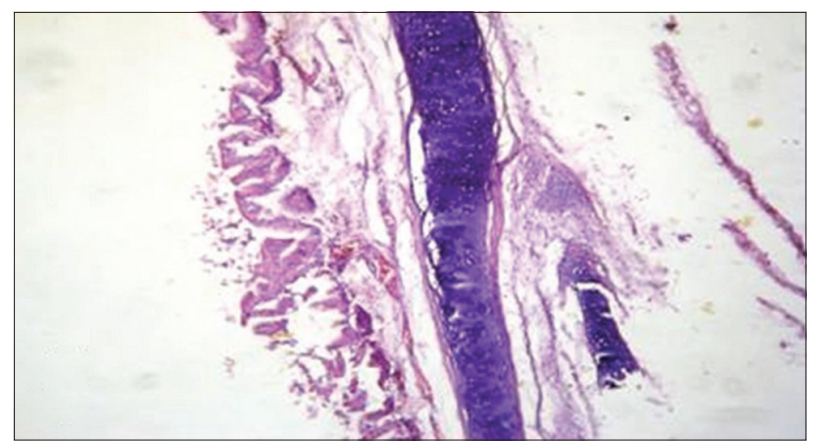

Figure-5: Trachea showing subcutaneous edema, congestion and mild desquamation $(\mathrm{H}$ and $\mathrm{E}, \times 300)($ Group 2$)$.

Table-1: Hemogram of normal and diseased ducks with H5N1 viruses (mean values $\pm \mathrm{SE}$ ).

\begin{tabular}{|c|c|c|c|c|c|c|}
\hline \multirow[t]{2}{*}{ Groups } & \multicolumn{6}{|c|}{ Parameters } \\
\hline & RBCs $\left(\times 10^{6} / \mu \mathrm{l}\right)$ & PCV (\%) & $\mathrm{Hb}(\mathrm{g} / \mathrm{dl})$ & MCV (FI) & MCH (pg) & MCHC (\%) \\
\hline 1 & $2.58 \pm 0.04$ & $37.75 \pm 0.28$ & $12.53 \pm 0.04$ & $146.25 \pm 2.56$ & $48.57 \pm 0.79$ & $33.23 \pm 0.24$ \\
\hline 2 & $2.15 \pm 0.05^{* *}$ & $28.90 \pm 0.54 * *$ & $8.45 \pm 0.09 * *$ & $134.86 \pm 4.47 *$ & $39.47 \pm 1.20 * *$ & $29.39 \pm 0.81 * *$ \\
\hline$\%$ difference & -16.66 & -23.44 & -32.56 & -7.78 & -18.73 & -11.55 \\
\hline
\end{tabular}

**Highly significant at $\mathrm{p} \leq 0.01, \mathrm{RBC}=$ Red blood corpuscles, $\mathrm{MCV}=$ Mean corpuscular volume, $\mathrm{Hb}=$ Hemoglobin, $\mathrm{MCH}=\mathrm{Mean}$ corpuscular hemoglobin, $\mathrm{PCV}=$ Packed cell volume, $\mathrm{MCHC}=$ Mean corpuscular hemoglobin concentration, $*$ Significant at $\mathrm{p} \leq 0.05$

Table-2: Leukogram and platelet count of normal and diseased ducks with H5N1 viruses (mean values $\pm \mathrm{SE}$ ).

\begin{tabular}{lccccc}
\hline Groups & \multicolumn{5}{c}{ Parameters $\left(\times \mathbf{1 0}^{\mathbf{3}} / / \mathbf{\mu l}\right)$} \\
\cline { 2 - 6 } & TLC & Heterophil & Lymphocyte & Monocyte & Platelet \\
\hline 1 & $18.17 \pm 0.21$ & $4.75 \pm 0.23$ & $11.37 \pm 0.30$ & $0.66 \pm 0.07$ & $16.10 \pm 0.41$ \\
2 & $14.47 \pm 0.57 * *$ & $3.89 \pm 0.27^{*}$ & $8.69 \pm 0.38^{* *}$ & $0.47 \pm 0.09^{N S}$ & $14.45 \pm 0.54 *$ \\
\% difference & -20.36 & -18.11 & -23.57 & -28.79 & -10.24 \\
\hline
\end{tabular}

**Highly significant at $\mathrm{p} \leq 0.01, \mathrm{TLC}=$ Total leukocytic count, SE=Standard error, *Significant at $\mathrm{p} \leq 0.05$

Veterinary World, EISSN: 2231-0916 
Table-3: Proteinogram of normal and diseased ducks with H5N1 viruses (mean values $\pm \mathrm{SE}$ ).

\begin{tabular}{lcccccc}
\hline Groups & \multicolumn{5}{c}{ Parameters $(\mathbf{g} / \mathbf{d l})$} \\
\cline { 2 - 7 } & Total protein & Albumin & Alpha1 globulin & Alpha2 globulin & Beta globulin & Gamma globulin \\
\hline 1 & $7.14 \pm 0.23$ & $4.41 \pm 0.23$ & $0.17 \pm 0.02$ & $0.78 \pm 0.06$ & $0.79 \pm 0.06$ & $0.98 \pm 0.04$ \\
2 & $5.45 \pm 0.30 * *$ & $3.50 \pm 0.29 *$ & $0.12 \pm 0.01 * *$ & $0.53 \pm 0.07 *$ & $0.48 \pm 0.07 * *$ & $0.82 \pm 0.05 *$ \\
\% difference & -23.66 & -20.63 & -29.41 & -32.05 & -39.24 & -16.32 \\
\hline
\end{tabular}

$* *$ Highly significant at $\mathrm{p} \leq 0.01, \mathrm{SE}=$ Standard error, *Significant at $\mathrm{p} \leq 0.05$

Table-4: Some serum enzymes of normal and diseased ducks with H5N1 viruses (mean values \pm SE).

\begin{tabular}{lcccccc}
\hline Groups & \multicolumn{5}{c}{ Parameters (U/I) } \\
\cline { 2 - 7 } & AST & ALT & ALP & GGT & LDH & CPK \\
\hline 1 & $14.57 \pm 0.27$ & $31.88 \pm 0.25$ & $130.08 \pm 0.48$ & $4.83 \pm 0.07$ & $246.73 \pm 1.81$ & $267.23 \pm 1.37$ \\
2 & $25.62 \pm 0.28^{* *}$ & $40.09 \pm 0.31^{* *}$ & $161.49 \pm 0.68^{* *}$ & $8.12 \pm 0.15^{* *}$ & $324.41 \pm 1.98^{* *}$ & $303.61 \pm 2.18^{* *}$ \\
\% difference & 75.84 & 25.75 & 24.15 & 68.12 & 31.48 & 13.61 \\
\hline
\end{tabular}

**Highly significant at $\mathrm{p} \leq 0.01, \mathrm{AST}=$ Aspartate aminotransferase, ALT=Alanine aminotransferase, ALP=Alkaline phosphatase, $\mathrm{GGT}=Y$-glutamyl transpeptidase, $\mathrm{LDH}=$ Lactate dehydrogenase, $\mathrm{CK}=$ Creatine phosphokinase, $\mathrm{SE}=\mathrm{Standard}$ error

Table-5: Some renal function tests of normal and diseased ducks with H5N1 viruses (mean values \pm SE).

\begin{tabular}{lcccc}
\hline Groups & \multicolumn{4}{c}{ Parameters $\mathbf{( m g / d \mathbf { ~ }}$} \\
\cline { 2 - 4 } & Creatinine & Uric acid & Ca & P \\
\hline 1 & $0.65 \pm 0.02$ & $2.85 \pm 0.39$ & $8.51 \pm 0.31$ & $4.50 \pm 0.12$ \\
2 & $0.79 \pm 0.02 * *$ & $5.97 \pm 0.68^{* *}$ & $7.65 \pm 0.15^{*}$ & $4.99 \pm 0.11^{* *}$ \\
$\%$ difference & 21.54 & 109.47 & -10.11 & 10.88 \\
\hline$* *$ Highly significant at $\mathrm{p} \leq 0.01, \mathrm{P}=$ Phosphorus, Ca=Calcium, SE=Standard error, *Significant at $\mathrm{p} \leq 0.05$ &
\end{tabular}

In addition, the presence of hypocalcemia, and hyperphosphatemia in the infected ducks compared with the normal. Hypocalcemia could be returned to decreased calcium absorption from the intestine, increased excretion or may be related to hypoalbuminemia [37,46]. Hyperphosphatemia may be combined to hypocalcemia which in turn led to an increase of the parathormone hormone [37]. These results confirmed by histopathological examination of the kidney which showed necrotic renal tubule and hemorrhage in renal parenchyma (Figure-7).

\section{Conclusion}

It could be concluded that the highly pathogenic AIV (A/H5N1) became more sever infectious to ducks than before and causes nervous manifestations and blindness which were un common in ducks. Besides the significant increases of hepatic enzymes, brain, heart and renal markers as a response to virus damage to these organs.

\section{Authors' Contributions}

EAM planned the study design, collected and examined samples, drafted and revised the manuscript, read and approved the final manuscript.

\section{Acknowledgments}

The author would like to thank Prof. Dr. AbdelMoneim A. Ali Professor and Head of Pathology Department, Faculty of Veterinary Medicine at Zagazig University for his help in examination of histopathological slides. This work was done on

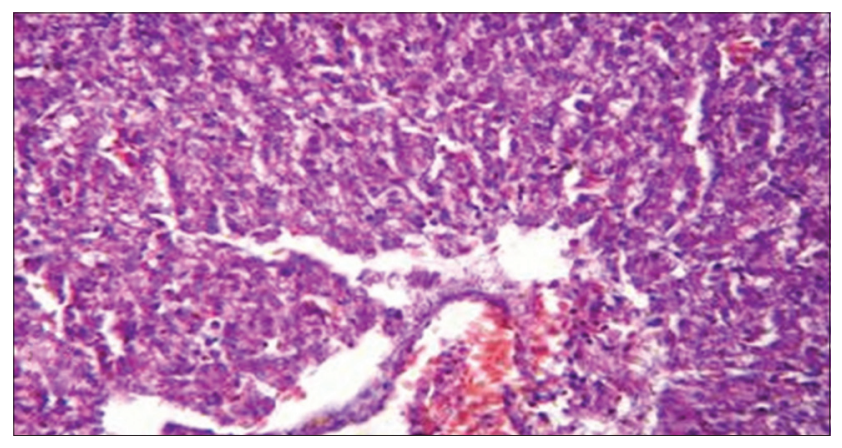

Figure-6: Liver showing degenerative and necrotic changes in hepatic tissue and Hemorrhage in portal area ( $\mathrm{H}$ and $\mathrm{E}, \times 1200)$ (Group 2).

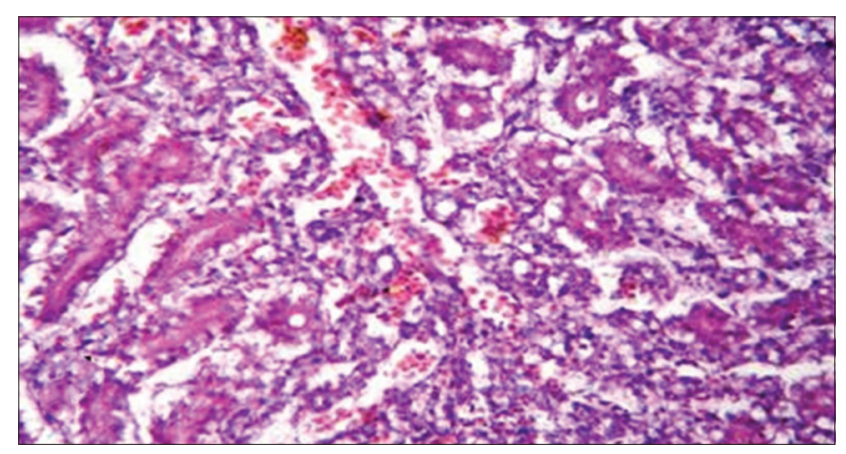

Figure-7: Kidney showing necrotic renal tubule and hemorrhage in renal parenchyma ( $H$ and $E, \times 1200)$ (Group 2).

author's expense without funding from any organization. Necessary facilities of Department of Clinical Pathology, Faculty of Veterinary Medicine, Zagazig University were used. 


\section{Competing Interests} interests.

The author declare that they have no competing

\section{References}

1. Husain, M. (2014) Avian influenza A (H7N9): Virus infection in humans: Epidemiology, evolution, and pathogenesis. Infect. Genet. Evol., 28: 304-12.

2. Abdelwhab, E.M. and Hafez, H.M. (2011) An overview of the epidemic of highly pathogenic H5N1 avian influenza virus in Egypt: Epidemiology and control challenges. Epidemiol. Infect., 139: 647-657.

3. Pantin-Jackwood, M.J., Costa-Hurtado, M., Miller, P.J., Afonso, C.L., Spackman, E. R. and Kapczynski, D. (2015) Experimental co-infections of domestic ducks with a virulent Newcastle disease virus and low or highly pathogenic avian influenza viruses. Vet. Microbiol., 177: 1016.

4. Pantin-Jackwood, M.J., Suarez, D.L., Spackman, E. and Swayne, D.E. (2007) Age at infection affects the pathogenicity of Asian highly pathogenic avian influenza H5N1 viruses in ducks. Virus Res., 130: 151-61.

5. Capua, I. and Mutinelli, F. (2001) Mortality in muscovy ducks (Cairina moschata) and domestic geese (Anser anser var. domestica) associated with natural infection with a highly pathogenic avian influenza virus of H7N1 subtype. Avian Pathol., 30: 179-183.

6. Löndt, B.Z., Núñez, A., Banks, J., Alexander, D.J., Russell, C. and Richard-Löndt, A.C. (2010) The effect of age on the pathogenesis of a highly pathogenic avian influenza (HPAI) H5N1 virus in Pekin ducks (Anas platyrhynchos) infected experimentally. Influenza Respir. Viruses, 4: 17-25.

7. Phuong, D.Q., Dung, N.T., Jørgensen, P.H., Handberg, K.J., Vinh, N.T. and Christensen, J.P. (2011) Susceptibility of muscovy (Cairina moschata) and mallard ducks (Anas platyrhynchos) to experimental infections by different genotypes of H5N1 avian influenza viruses. Vet. Microbiol., 148: 168-174.

8. Bröjer, C., Järhult, J.D., Muradrasoli, S., Söderstrom, H., Olsen, B. and Gavier-Widén, D. (2013) Pathobiology and virus shedding of low pathogenic avian influenza virus (A/H1N1) infection in mallards exposed to oseltamivir. $J$. Wildlife Dis., 49: 103-113.

9. de Vries, E., Guo, H., Dai, M., Rottier, P.J.M., van Kuppeveld, F.J.M. and de Haan, C.A.M. (2015) Rapid emergence of highly pathogenic avian influenza subtypes from a subtype $\mathrm{H} 5 \mathrm{~N} 1$ hemagglutinin variant. Emerg. Infect. Dis., 21: 842-846.

10. Brown, I.H. (2010) Summary of avian influenza activity in Europe, Asia, and Africa, 2006-2009. Avian Dis., 54: 187-193.

11. Vandegrift, K.J., Sokolow, S.H., Daszak, P. and Kilpatrick, A.M. (2010) Ecology of avian influenza viruses in a changing world. Ann. N. Y. Acad. Sci. US., 1195: 113-128.

12. Sonnberg, S., Webby, R.J. and Webster, R.G. (2013) Natural history of highly pathogenic avian influenza H5N1. Virus. Res., 178: 63-77.

13. Soda, K., Ito, H., Usui, T., Nagai, Y., Ozaki, H. and Yamaguchi, T. (2013) Incursion and spread of H5N1 highly pathogenic avian influenza viruses among wild birds in 2010-11 winter in Japan. J. Vet. Med. Sci., 75: 605-612.

14. Nemeth, N.M., Brown, J.D., Stallknecht, D.E., Howerth, E.W., Newman, S.H. and Swayne, D.E. (2013) Experimental infection of bar-headed geese (Anser indicus) and ruddy shelducks (Tadorna ferruginea) With a Clade 2.3.2 H5N1 highly pathogenic avian influenza virus. Vet. Pathol., 50(6): 961-970.

15. Natt, M. and Herrick, C. (1953) A new blood diluent for counting the erythrocytes and leukocytes of the chickens. Poult. Sci., 31: 735-738.
16. Feldman, B., Zinki, J. and Jain, V.S. (2000) Veterinary Hematology. $5^{\text {th }}$ ed. Lippincott Williams and Wilkins, Canada.

17. Zijlstra, N. (1960) Estimation of hemoglobin. Clin. Chem. Acta., 5: 719.

18. Reitman, S. and Frankel, S. (1957) A colorimetric method for determination of serum glutamicoxaloacetic transaminase and serum glutamic pyruvic transaminase. Am. J. Clin. Pathol., 25: 56.

19. Persijn, J.P. and van der Slik, W. (1976) A new method for the determination of $\gamma$-glutamyltransferase in serum. $J$. Clin. Chem. Clin. Biochem., 14: 421-427.

20. Lum, G. and Gambino, R.S. (1974) A comparison of serum versus heparinized plasma for routine chemistry tests. $\mathrm{Am}$. J. Clin. Pathol., 61: 108-113.

21. Henry, T.J. (1974) Determination of serum creatinine. Clinical Chemistry: Principles and Techniques. $2^{\text {nd }}$ ed. Harper and Row Publishers, New York.

22. Sanders, G.T.B. and Pasman, A.J. (1980) Determination of serum uric acid. Clin. Chem. Acta., 101: 299-303.

23. Tietz, N.W. (1970) Determination of Serum Calcium. W.B. Saunders Company, Philadelphia, London.

24. Goodwin, J.F. (1970) Determination of serum phosphorus. Clin. Chem., 16: 776-780.

25. Laurell, C. (1966) Quantitative estimation of proteins by electrophoresis in agarose gel containing antibodies. Anal. Biochem., 15: 45-52.

26. Bancroft, J., Stevens, A. and Turner, D. (1996) Theory and Practice of Histopathological Techniques. $4^{\text {th }}$ ed. Churchill Livingstone, New York.

27. Njouom, R., Aubin, J.T., Bella, A.L., Demsa, B.M., Rouquet, P. and Gake, B. (2008) Highly pathogenic avian influenza virus subtype $\mathrm{H} 5 \mathrm{~N} 1$ in ducks in the Northern part of Cameroon. Vet. Microbiol., 130: 380-384.

28. Tamhane, A. and Dunlop, D. (2000) Statistic and Data Analysis from Elementary to Intermediate. Prentice Hall, Upper Saddle River, New Jersey, USA.

29. Enserink, M. (2006) Avian influenza. H5N1 moves into Africa, European Union, deepening global crisis. Science, 311: 932

30. Rhyoo, M.Y., Lee, K.H., Moon, O.K., Park, W.H., Bae, Y.C. and Jung, J.Y. (2015) Analysis of signs and pathology of H5N1-infected ducks from the 2010-2011 Korean highly pathogenic avian influenza outbreak suggests the influence of age and management practices on severity of disease. Avian Pathol., 44: 175-181.

31. Hagag, I.T., Mansour, S.M., Zhang, Z., Ali, A.A., Ismaiel, B.M. and Salama, A.A. (2015) Pathogenicity of highly pathogenic avian influenza virus $\mathrm{H} 5 \mathrm{~N} 1$ in naturally infected poultry in Egypt. PLoS One. 10: e0120061.

32. Reperant, L.A., Bildt, M.W.G., Amerongen, G., Buehler, D.M., Osterhau, A.D. and Jenni-Eiermann, S. (2011) Highly pathogenic avian influenza virus H5N1 infection in a long-distance migrant shorebird under migratory and non-migratory States. PLoS One, 6: e27814.

33. Kim, H.R., Kwon, Y.K., Jang, I., Lee, Y.J., Kang, H.M. and Lee, E.K. (2015) Pathologic changes in wild birds infected with highly pathogenic avian influenza A(H5N8) Viruses, South Korea, 2014. Emerg. Infect. Dis., 21: 775-780.

34. Kwon, Y.K., Thomas, C. and Swayne, D.E. (2010) Variability in pathobiology of South Korean H5N1 high-pathogenicity avian influenza virus infection for 5 species of migratory waterfowl. Vet. Pathol., 47: 495-506.

35. Matsuda, K., Park, C.H., Sunden, Y., Kimura, T., Ochiai, K. and Kida, H. (2004) The vagus nerve is one route of transneural invasion for intranasally inoculated influenza a virus in mice. Vet. Pathol., 41: 101-107.

36. Mori, I., Komatsu, T., Takeuchi, K., Nakakuki, K., Sudo, M. and Kimura, Y. (1995) Viremia induced by influenza virus. Microbiol. Pathol., 19: 237-244.

37. Coles, E. (1986) Veterinary Clinical Pathology. $2^{\text {nd }}$ ed. W.B. Saunders Company, Philadelphia, London. 
38. Benjamin, M. (1998) Hematology. In Out line of Veterinary Clinical Pathology. $3^{\text {rd }}$ ed. Kalyani Publishers, New Delhi.

39. Swayne, D.E. and Pantin-Jackwood, M. (2006) Pathogenicity of avian influenza viruses in poultry. Dev. Biol., (Basel)., 124: 61-67.

40. Acland, H.M., Silverman Bachin, L.A. and Eckroade, R.J. (1984) Lesions in broiler and layer chickens in an outbreak of highly pathogenic avian influenza virus infection. Vet. Pathol., 21: 564-569.

41. Lin, F., Gao, C., Chen, S., Zhu, X., Cheng, X. and Wang, S. (2011) Immunosuppression effect of co-infection with MDRV and H9 AIV on thymus in muscovy ducks. Wei Sheng Wu Xue Bao, 51: 1407-1412.
42. Kaneko, J.J., Harvey, J.W. and Bruss, M.L. (1997) Clinical Biochemistry of Domestic Animals. $5^{\text {th }}$ ed. Academic Press, California, USA.

43. Goldberg, D.M. (1980) Structural, functional, and clinical aspects of gamma-glutamyltransferase. CRC Crit Rev. Clin. Lab. Sci., 12: 1-58.

44. Wallimann, T. and Hemmer, W. (1994) Creatine kinase in non-muscle tissues and cells. Mol. Cell Biochem., 133-134: 193-220.

45. Galvin, C.E. (1980) Colorimetric test for determination of uric acid. Clin. Chem., 26: 227.

46. Nasr El-Deen, N. (2007) Clinicopathological studies on naturally infected chickens with avian influenza. Zagazig Vet. J., 35: 203-210.

$* * * * * * * *$ 